Photochemistry

\section{Selective chemistry}

\section{in a capsule}

\section{J. Am. Chem. Soc. doi:10.1021/ja0450197 (2004)}

Chemists have constructed a bowl-shaped molecule that, when it dimerizes in water, traps smaller guest molecules inside and activates them so that they react with light. This 'cavitand' therefore seems to mimic the behaviour of enzymes. Although the cavitand is soluble in water, its inside is dry and hydrophobic, and so attracts certain carbon-based molecules that would otherwise shy away from water.

Lakshmi S. Kaanumalle et al. report that when the capsule encloses the small molecules, it causes a very specific light-driven reaction to occur. The cage effect inhibits all but the desired reaction pathway, a selectivity that has previously been seen only in solid-state reactions.

In one particular experiment, the authors note that the cavitand promotes an unusual reaction pathway in which a highly reactive intermediate, called a radical pair, must exist for much longer than normal. They also claim that, during the reaction, part of the guest molecule twists, rearranging its carbon skeleton in a precise way that is controlled by its host.

Mark Peplow

\section{Medicine}

\section{Simple SARS detection}

Emerg. Infect. Dis. Nov. (2004)

www.cdc.gov/ncidod/EID/vol10no11/04-0516.htm

The outbreak of severe acute respiratory syndrome (SARS) in 2003 left hundreds of people dead. It also left scientists scrambling to find the best way of detecting the virus early on to prevent its spread. The availability of the complete genomic sequence of the coronavirus that causes SARS has allowed rapid detection. But these tests require familiarity with the high-tech equipment for carrying out assays such as reverse transcription and the polymerase chain reaction.

Xiao-Yan Che et al. have looked at the advantages of using the nucleocapsid protein, or ' $\mathrm{N}$ protein', of the coronavirus as a diagnostic marker. They analysed 420 serum samples taken from 317 SARS patients, and found that the protein could be detected as early as day 1 after the onset of symptoms and until day 18. Using a specially developed immunosorbent assay, they were able to establish $\mathrm{N}$-protein concentrations in the samples. The approach resulted in a test specificity of $99.9 \%$.

The technique could be used in medical centres lacking sophisticated equipment, the authors say, and in mass screening to track the origins of SARS.

\section{Microbiology}

\section{Sticky insects}

Cell 119, 329-341 (2004)

The parasite Leishmania causes the sometimes fatal tropical disease leishmaniasis, and is transmitted to humans by the bite of the sand fly. Shaden Kamhawi et al. have now identified a protein that helps the pathogen attach to, and survive in, the sand fly's digestive tract.

The researchers screened a library of genes that are active in the midgut of the sand fly Phlebotomus papatasi, and found that one gene encodes a member of a family of proteins called galectins, which are involved in insect immunity against pathogens.
Kamhawi et al. present evidence that the parasite binds to this protein, called PpGalec, and uses it to latch on to the insect's gut. When the authors fed sand flies with an antibody that binds and blocks PpGalec, the number of parasites in the gut dropped dramatically and the infection was often eliminated altogether.

The authors speculate that using molecules such as PpGalec in vaccines enabling antibodies against these molecules to be produced in humans or other animal reservoirs - could stop the parasite from gaining a foothold in sand flies after they bite an infected host, and thereby interrupt the transmission cycle.

Helen Pearson

\section{Natural-product chemistry}

\section{A toxic trail}

Proc. Natl Acad. Sci. USA 45, 15857-15860 (2004)

Native Colombian Indians dip their blow-darts in a poison obtained from the skins of certain species of frog. The major components of the poison, called batrachotoxins, are 250 times more toxic than strychnine. They are not made by the frogs themselves, however, and their apparent dietary origin had remained a mystery.

The same toxins have also been identified in the feathers and skin of birds of the genera Pitohui (pictured) and Ifrita endemic to New Guinea, where they seem to act as a deterrent to parasites and predators, including humans. Now John P. Dumbacher et al. have found out how the birds acquire their batrachotoxins. Following up a suggestion by local people, they identified these toxins in 'nanisani' beetles of the genus Choresine. The local word 'nanisani' refers to the tingling and numbing sensation that comes from contact with either these Choresine beetles or the Ifrita birds; the villagers warned how beetles landing in an eye or on one's face can cause painful burning.

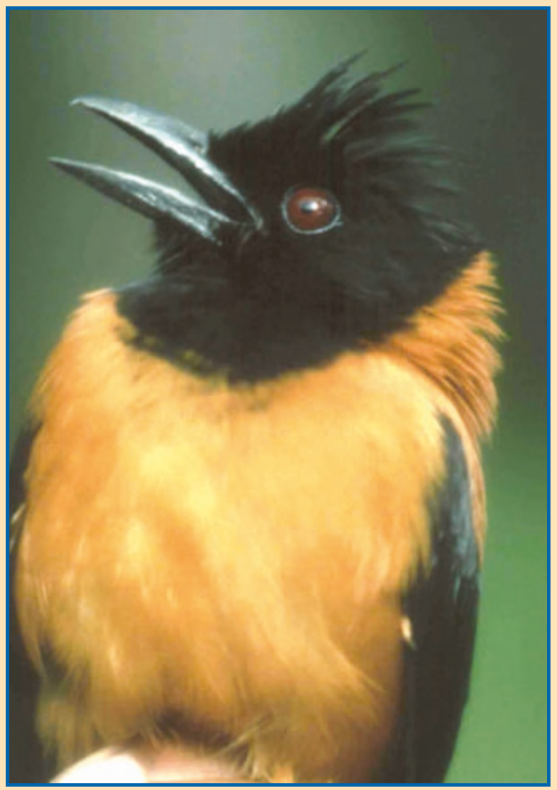

The beetle can't make the complex steroidal carbon skeletons of the batrachotoxins. Presumably, either the beetle, or perhaps some symbiotic organism, modifies steroids acquired from plant sources to make these deadly substances.

Philip Ball

\section{Addiction \\ Nicotine sensitivity \\ Science 306, 1029-1032 (2004)}

Nerve cells in various parts of the central nervous system bear a receptor for the neurotransmitter acetylcholine. This receptor is also what enables nerves to respond to nicotine - and it is nicotine's addictive properties that are thought to make giving up smoking so difficult.

Twelve different subunits of the receptor have been identified, and they can combine in different ways to make up the pentameric protein. Andrew R. Tapper et al. genetically engineered mice to bear a mutation in the $\alpha 4$ subunit that made the $\alpha 4$-containing receptors hypersensitive to nicotine. They found that the animals required far lower doses of nicotine than controls to display such addictive symptoms as sensitization, tolerance and a preference for nicotine-containing solutions over saline. It seems that this subunit alone is sufficient to engender addiction.

These mice should, the authors say, be good subjects for further molecular and behavioural studies. The findings also raise the possibility that individual variations in the $\alpha 4$ subunit might underlie people's differing susceptibility to nicotine addiction.

Amanda Tromans 